\title{
Article \\ Analysis of Different Stop-Jumping Strategies on the Biomechanical Changes in the Lower Limbs
}

\author{
Huiyu Zhou ${ }^{1,2}$, Datao Xu ${ }^{1}$, Chaoyi Chen ${ }^{1,2}$, Ukadike Chris Ugbolue ${ }^{2}\left(\right.$, Julien S. Baker ${ }^{3}{ }^{(1)}$ and Yaodong Gu ${ }^{1, *(1)}$ \\ 1 Faculty of Sports Science, Ningbo University, Ningbo 315211, China; zhouhuiyu@aliyun.com (H.Z.); \\ xudatao3@gmail.com (D.X.); chencarol@aliyun.com (C.C.) \\ 2 School of Health and Life Sciences, University of the West of Scotland, Scotland G72 0LH, UK; \\ U.Ugbolue@uws.ac.uk \\ 3 Centre for Health and Exercise Science Research, Department of Sport and Physical Education, \\ Hong Kong Baptist University, Hong Kong 999077, China; jsbaker@hkbu.edu.hk \\ * Correspondence: guyaodong@nbu.edu.cn; Tel.: +86-574-8760-0208
}

Citation: Zhou, H.; Xu, D.; Chen, C.; Ugbolue, U.C.; Baker, J.S.; Gu, Y. Analysis of Different Stop-Jumping Strategies on the Biomechanical Changes in the Lower Limbs. Appl. Sci. 2021, 11, 4633. https://doi.org/ 10.3390/app11104633

Academic Editor: Chi-Seung Lee

Received: 10 April 2021

Accepted: 13 May 2021

Published: 19 May 2021

Publisher's Note: MDPI stays neutral with regard to jurisdictional claims in published maps and institutional affiliations.

Copyright: (c) 2021 by the authors. Licensee MDPI, Basel, Switzerland. This article is an open access article distributed under the terms and conditions of the Creative Commons Attribution (CC BY) license (https:/ / creativecommons.org/licenses/by/ $4.0 /)$.
Abstract: The stop-jumping task is one of the most important technical actions in basketball. A previous study showed $70 \%$ probability of non-contact ACL injuries during stop-jumping tasks. Therefore, the present study aimed to investigate the differences in lower extremity biomechanical changes between the rear foot as the initial contact area to terminate the jump (SJR) and the fore foot as the initial contact area to also terminate the jump (SJF) during the horizontal landing during a stop-jumping phase. In total, 25 male amateur Ningbo University basketball athletes from China were recruited for this study. The participants were asked to jump vertically by using two different stop-jumping strategies. Kinematic and kinetics data were amassed during a stop-jumping task. Statistical parametric mapping (SPM) analysis was used to find the differences between SJR and SJF. Our results indicated that the change of different ankle range of motion caused significantly different values for knee angle $(p<0.001)$, velocity $(p=0.003)(p=0.023)(p<0.001)$, moment $(p=0.04)$ $(p<0.001),(p=0.036)$ and power $(p=0.015)(p<0.001)$ during the stop-jumping phase and the horizontal landing phase. The same biomechanical parameters of the hip joint were also significantly different for hip angle $(p<0.001)$, moment $(p=0.012)(p<0.001)(p<0.001)$, and power $(p=0.01)$ $(p<0.001)(p<0.001)$. These findings indicate that altering the primary contact at the ankle angle might effectively reduce the risk of a knee injury.

Keywords: stop-jumping task; horizontal landing phase; landing injury; statistical parametric mapping

\section{Introduction}

Termination tasks are common movements in basketball, volleyball, and soccer [1,2]. These movements include stop-jumping, landing and side-cutting, etc. According to a previous study, these types of termination tasks could cause significant injuries to athletes and have a significant effect on competition performance. This is related to the fact that athletes place large loadings on their knee joints repeatedly during the performance of these tasks [3]. Many researchers have attempted to seek as much information as possible about the in vivo mechanism or cause of injuries before they occur. An example of this is the parameters of biomechanical of the lower limbs as an essential index for injury prevention [4]. The stop-jumping task is one of the most important technical actions used in basketball, and it can be divided into three steps. Lin and Paul define what a complete stop-jumping task is [5,6], whereby the participant performs an approach run, then immediately stops (horizontal landing phase), and finally takes off.

Anterior cruciate ligament (ACL) injuries were studied for many years [7-11], and many researchers attempted to help athletes decrease ACL injuries when performing a sharp deceleration task $[12,13]$. These include stop-jumping, a quick stop, or a cutting maneuver. A previous review observed that there was $70 \%$ chance of non-contact ACL 
injuries in stop-jumping tasks [14]. Therefore, we need to understand what the key information required is for understanding the biomechanical parameters before ACL injuries occur. The knee flexion angle is one of the most important indexes to reflect ACL injuries. According to previous studies, a higher ground reaction force (GRF) on the vertical landing could impact the lower angle of knee flexion at the horizontal landing phase during the stop-jumping task. As a result, decreasing the angle of knee flexion could raise the loading on the ACL [15-19]. The angle of knee flexion needs to be considered as a significant biomechanical parameter for evaluating ACL injuries.

Further reasons for detecting the cause of ACL injury are that many patients following reconstruction of ACL surgery commonly suffer potential risks for further injury. Previous studies followed patients who accepted the reconstruction of ACL surgery [20,21], and they found that there was a 30-35\% chance for the patient to suffer a second ACL injury. The body is supported by the legs separately, and if one side undergoes cruciate ligament reconstruction, the load of the lower extremity on the other side is inevitably increased. This is one of the most important highlighted risks for patients who suffered second ACL injuries [22-27]. Paterno further demonstrated that the knee extension moment was a further biomechanical parameter for consideration when reconstructed ACL surgery patients performed landing mechanics [25]. A previous study focused on patient follow up after reconstruction of the ACL, and they noted that $87 \%$ patients had the potential of osteoarthritis following the results of an imaging test, with $45 \%$ needing re-surgery and with only $23 \%$ of patients being content with their function of the knee [28].

Posterior ground reaction force (PGRF) and proximal tibia anterior shear force (PTASF) are more likely to reflect or present the signs of ACL injuries. Previous studies revealed that this can be the most direct loading mechanism for ACL injuries [29]. This research analyzed PTASF by using a simulation of biomechanical parameter indexes, and the researchers proved that PTASF raises the drawer force of the anterior of the knee, which has a positive correlation with ACL injuries. As for the index of PGRF, the study previously indicated that many different movements contributed to non-contact ACL injuries, because they have the same characteristics mimicking a sharp deceleration of the body [1,30,31]. Timothy believed that the knee joint produces an external force that requires an internal quadriceps force to counteract the external force generated [32]. According to these studies, the lack of quadriceps muscle strength is one possible cause of non-contact ACL injuries.

Many studies focused on landing techniques that could be using different strategies to reduce impact from vertical ground reaction forces (VGRF). A greater angle of the ankle at initial contact could reduce GRF vertically when performing a landing task, and this strategy could raise the ankle range of motion, thus reducing the impact of GRF [33-35]. Using this technique, the landing could have a higher knee flexion and less impact on soft tissue. Malliaras believed that lower ankle dorsiflexion could decrease the risk of patellar tendinopathy [35]. The second step of stop-jumping is the horizontal landing phase, and this may require different strategies to reduce injuries. For example, we may consider changing the initial contact area of the foot when performing a stop-jumping task for achieving a greater knee flexion angle or decreasing the vertical reaction force. Thus far, no present studies are investigating biomechanical parameters that use the fore foot as an initial contact for the stop-jumping task. Normally, the rear foot is used and is a preference of most athletes. It is necessary, therefore, to explore the biomechanical changes of the lower extremities when the fore foot or the rear foot perform stop-jumping as an initial contact strategy.

This study aimed to investigate the differences in lower limb biomechanical changes between SJR and SJF during a stop-jumping phase in the horizontal landing. We hypothesized that SJF might be different for GRF, PGRF, ankle, and knee for angle, velocity, moment, and power compared with SJR. We further hypothesized SJF might have a lower knee joint vertical force than SJR in stop-jumping during the horizontal landing phase and PTASF. Meanwhile, these differences would reduce stop-jumping injury or provide better movement guidance from the perspective of biomechanics. 


\section{Methods}

\subsection{Participants}

In total, 25 male amateur Ningbo University basketball athletes from China were recruited for this study (age $23.4 \pm 1.14$ years, height $189.3 \pm 4.95 \mathrm{~cm}$, body weight (BW) $87.8 \pm 7.05 \mathrm{~kg}$ ). To ensure the participants' subject standardization, several inclusion criteria were used for the recruitment. These included: (1) all the participants were young, healthy, amateur basketball athletes playing in the Ningbo University basketball team; (2) every participant engaged in basketball three times a week (at least) and participated in basketball practice for two hours at a time; (3) there were no injuries of any kind on the lower limbs in the last six months, and there were no medical issues that could impact the experimental results; (4) there was no prior surgery performed on the lower limbs. Prior to experimental collection of data, all participants were notified about testing, including purpose, procedures, conditions, and requirements of the present study. All study information was contained and provided on a form of consent that was signed by all subjects. The present study was approved by the Ningbo University Ethics Committee (protocol code RAGH 20200603).

\subsection{Experiment Protocol}

All tests were enacted in the sports biomechanics lab at the University of Ningbo Research Academy of Grand Health. A motion capture system (Vicon) (Oxford Metrics Ltd., Oxford, UK) with 8 cameras was employed to collect the kinematic data of participants moving during the stop-jumping task. The frequency was set at $100 \mathrm{~Hz}$ for sampling. A force platform (Kistler, Switzerland) was set at $1000 \mathrm{~Hz}$ sampling frequency for the collection of kinetic data when performing the stop-jumping task. These two experimental facilities were conducted synchronously. Tight shorts and pants were worn by all participants. Based on a previous study, there were 20 diameters with $12.5 \mathrm{~mm}$ reflective markers secured onto each participant for the identification of motion patterns during each trial. Figure 1 shows the placement of each marker [36].

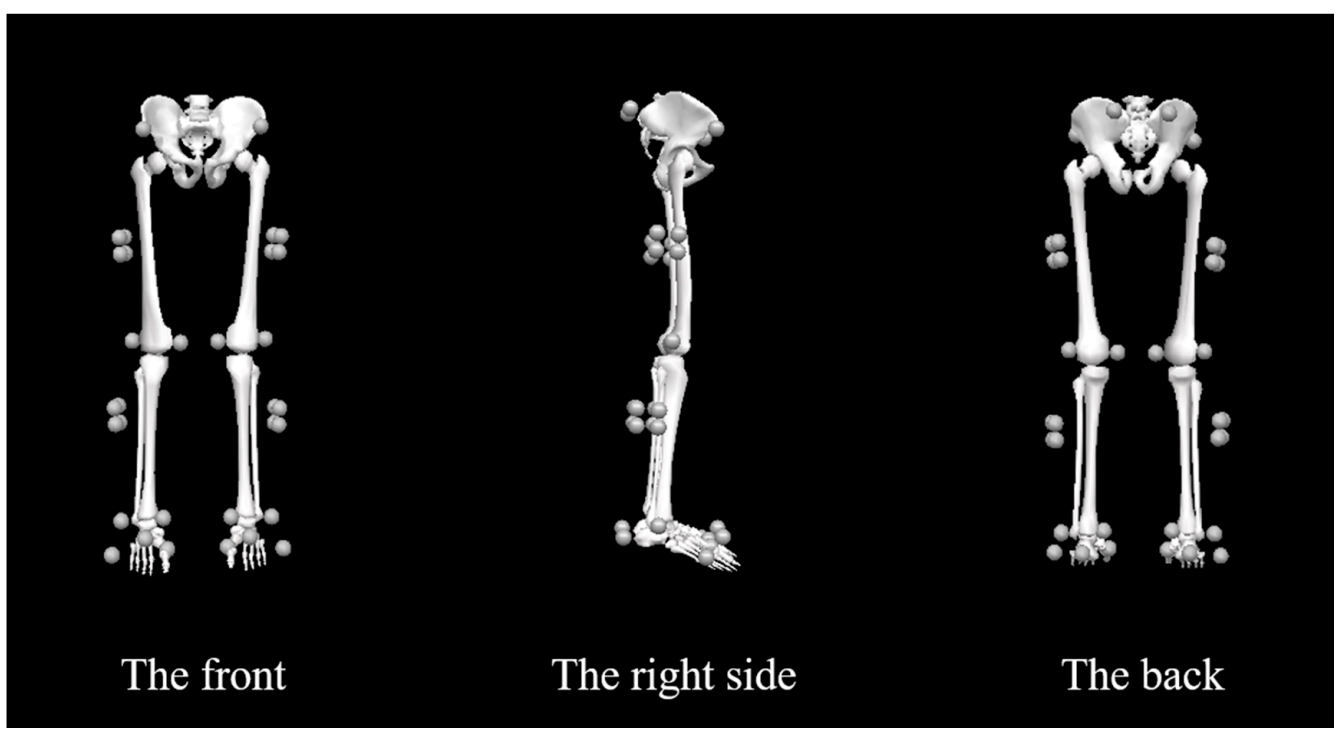

Figure 1. Illustration of each maker placement on the front, the right, and the back side.

\subsection{Procedure}

Participants were asked to warm up for $10 \mathrm{~min}$ on the treadmill (speed: $8 \mathrm{~km} / \mathrm{h}$ ). The subjects then performed stretching exercises to ensure that each participant could perform to their best potential during the experiment. Participants wore the same tight shirts and shoes as required for the formal experiment. There were three opportunities for each participant to adapt to the movements of the test. After the stage of warm up, full 
testing procedures were performed to minimize learning effects and to fully familiarize subjects with experimental conditions and procedures. After the markers were attached, the participants were instructed to stand on the force plate to collect static coordinates before formal experimental data collection began. Each participants' feet were parallel to the $Y$-axis, and their eyes remained motionless, looking forward until the end of the static data collection period.

For biomechanical data collection, each participant accelerated forward for four steps running toward the force platform, then immediately stopped and took-off. There was a four steps area circled on the ground to guide participants on how to complete the stop-jumping task. There were two stop-jumping strategies used in our study. (1) Figure 2 shows the fore foot as the initial contact area to stop the jump (SJF). (2) Figure 3 shows the rear foot as the initial contact area to stop the jump (SJR). The subjects were required to jump vertically as high as they could [37-39]. The data collected only referred to the left leg, which was defined as the dominant leg that was used to complete a single-leg jumping task.

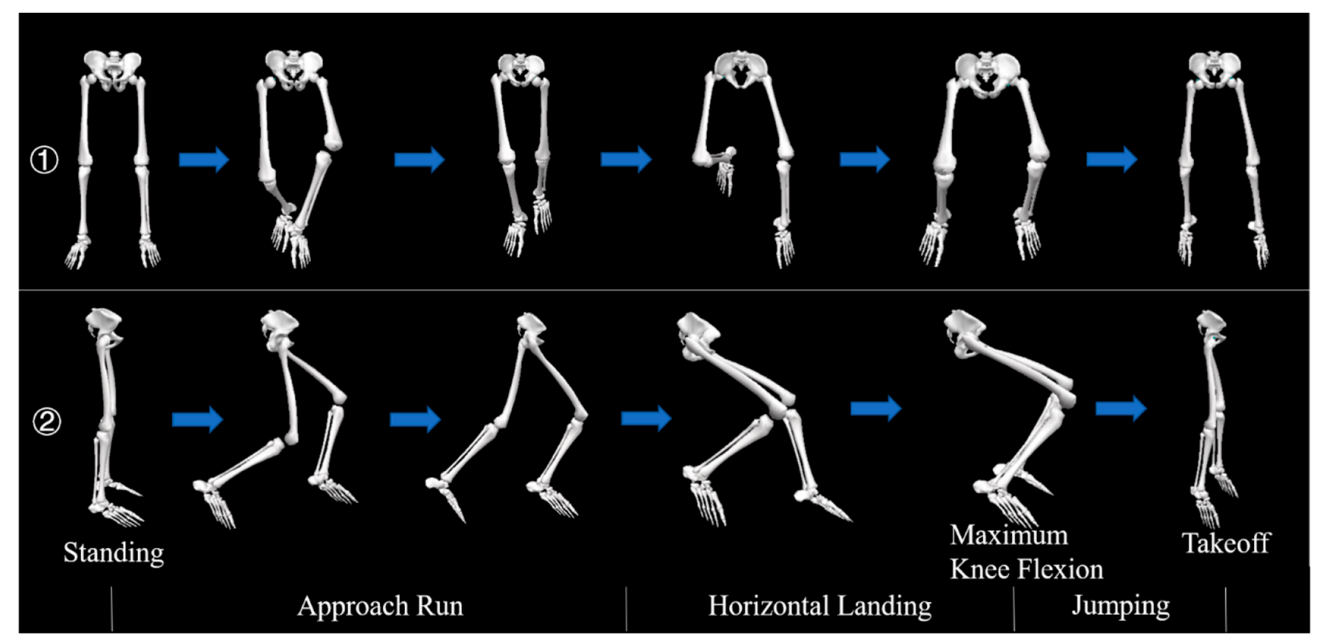

Figure 2. Illustration the fore foot performing stop-jumping as an initial contact; lines 1 and 2 are the front and the right side view.

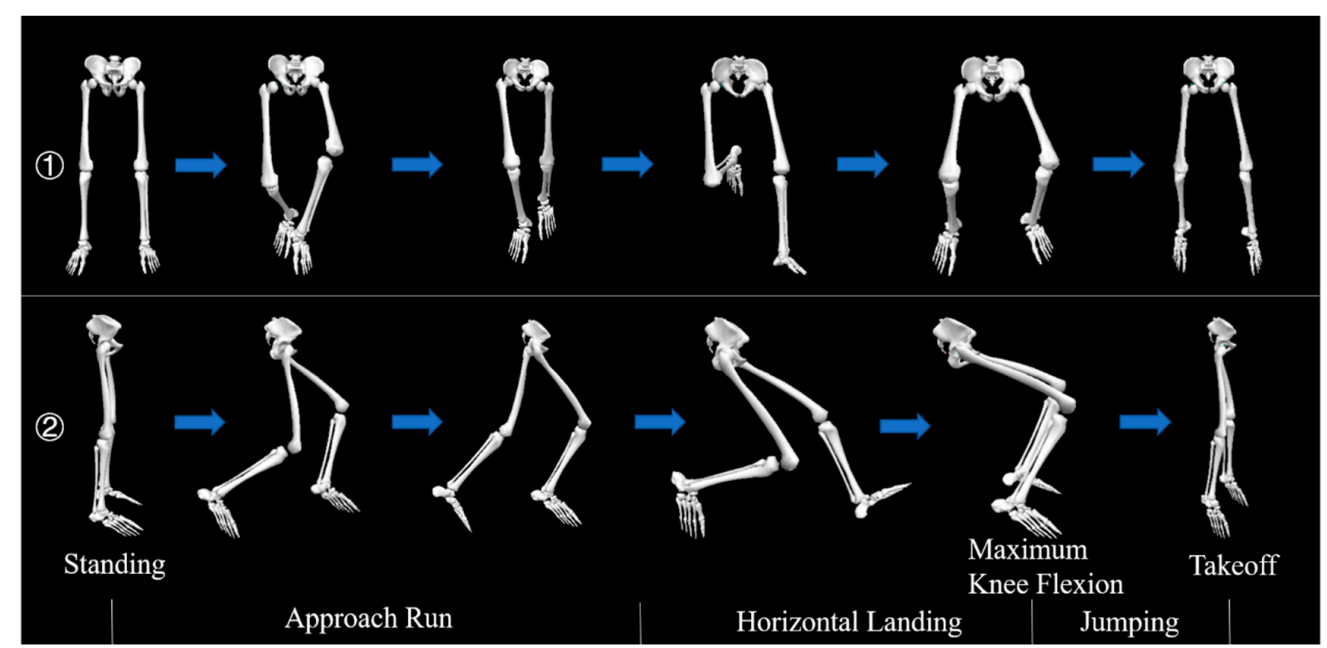

Figure 3. Illustration the rear foot performing stop-jumping as an initial contact; lines 1 and 2 are the front and the right side view.

During the stop-jumping task, if participants recorded any kind of non-vertical jumping or slide movements on their feet, the experiment was recorded as a failure. The dominant leg was used to collect 7 successful data sets, which equated to a total of 14 data 
sets for each participant using both types of stop-jumping strategies. There was a one minute break between each stop-jumping task to avoid any undue fatigue in participants. This was important, as individual fatigue could cause inaccuracies in data collection.

\subsection{Data Collection and Processing}

This study focused on lower biomechanical parameter changes using different stopjumping strategies. Visual 3D (c-motion Inc., Germantown, MD, USA) is customized software used as a functional tool to calculate and process kinetic and kinematic changes on the sagittal plane (ankle, knee, and hip joint velocity, angle, power, and moment). C3D files were used to generate from Vicon Software. The vertical surface reaction force exceeding $10 \mathrm{~N}$ was set as the initial contact [40]. The filter description of the frequency of use [41] was designed in accordance with Winter. The VGRF residual analysis was included in the subsets to confirm which was the most suitable signal-to-noise ratio. The data of the test for VGRF and kinematics were filtered by 20 and $10 \mathrm{~Hz}$ fourth-order zero-phase lag Butterworth low-pass filters. The data were imported into MATLAB R2019a (The MathWorks, MA, United States), and an edited code was applied for further analysis. The initial ground contact to the maximum flexion of the knee was defined as the horizontal landing phase. The maximum flexion of the knee to the force plate value zero was defined as the jumping phase.

The positive value was defined as knee and hip extension and dorsiflexion of the ankle, and the negative value was defined as knee and hip extension and plantarflexion of the ankle. The negative work (horizontal landing phase) values indicated the dissipation of energy through muscular eccentric contractions. Therefore, the contribution of the joint of individual work to the total dissipation of energy was used to calculate the percentage of the joint energy dissipation in the total energy dissipation (ankle, hip, and knee joints) [42] The positive work (jumping phase) values indicated energy export. Body mass was used to normalize the joint work. Dynamics of inverse were used to calculate the joint reaction of knee force, which transferred to the tibia reference frames and was deconstructed into PTASF [9].

\subsection{Statistical Analysis}

The normality test of Shapiro Wilk test was applied to all experimental data before statistical analysis. If nonconformity was observed, then the signed-rank of Wilcoxon matched-pairs test was used for non-parametric data. Paired $t$-tests assessed differences in kinematic and kinetic changes between different stop-jumping strategies.

In the SPM analysis, all kinematics and kinetic data of the stop-jumping phase were extracted, and a customized MATLAB script was used to expand the data points into a time series curve of 101 data points (representing $0 \%$ to $100 \%$ of the landing phase). Then, we used the open source SPM1d script of the paired-sample $t$-test for statistical analysis and set the significance threshold to $0.05[43,44]$.

For the analysis of traditional discrete variables, a MATLAB script was written to extract all data from the stop-jumping phase. All analyses of traditional discrete variables were carried out using SPSS 25.0 for Windows ${ }^{\mathrm{TM}}$ software (IBM, Armonk, NY, USA). $p<0.05$ was set as significant differences.

\section{Results}

The initial ground contact to the maximum flexion of the knee was defined as the horizontal landing phase (before the blue line in the resulting figure). The maximum knee flexion to the force plate value zero was defined as the jumping phase (after the blue line in the resulting figure). Table 1 shows an illustration of comparison points. 
Table 1. Illustration of comparison points.

\begin{tabular}{|c|c|c|}
\hline \multicolumn{2}{|c|}{ Statistical Parametric Mapping } & Paired $t$-Tests \\
\hline \multicolumn{2}{|c|}{ A stop-jumping phase } & A stop-jumping phase \\
\hline Horizontal landing phase & Vertical jumping phase & Peak value \\
\hline SJR vs. SJF & SJR vs. SJF & SJR vs. SJF \\
\hline
\end{tabular}

\subsection{Statistical Parametric Mapping}

3.1.1. Joint Angle, Velocity, Moment, and Power on the Sagittal Plane

- Horizontal landing phase

Figure 4 displays the significant differences for ankle angle, velocity, moment, and power during the horizontal landing phase between SJR and SJF. Significantly different values were ankle angle $(p=0.013)(p=0.018)(p<0.001)$, velocity $(p<0.001)(p<0.001)$, moment $(p<0.001)$, and power $(p<0.001)(p<0.001)$.

Figure 5 displays the significant differences for knee angle, velocity, moment, and power during horizontal landing phase between SJR and SJF. Significant different values were knee angle $(p<0.001)$, velocity $(p=0.003)(p=0.023)(p<0.001)$, moment $(p=0.04)$ $(p<0.001)(p=0.036)$, and power $(p=0.015)(p<0.001)$.

Figure 6 displays the significant differences for angle, velocity, moment, and power of the hip during the horizontal landing phase between SJR and SJF. Significantly different values were hip angle $(p<0.001)$, moment $(p=0.012)(p<0.001)(p<0.001)$, and power $(p=0.01)(p<0.001)(p<0.001)$. During the horizontal landing phase, there was no significant difference found in velocity of the hip.

- Vertical jumping phase

Figure 4 displays the significant differences for ankle angle, velocity, moment, and power during the vertical jumping phase between SJR and SJF. Significantly different values were ankle angle $(p<0.001)$, velocity $(p=0.01)$, moment $(p<0.001)(p<0.001)$, and power $(p<0.001)(p<0.001)$.

Figure 5 displays the significant differences for knee angle, velocity, moment, and power during the vertical jumping phase between SJR and SJF. Significantly different values were knee velocity $(p=0.004)$, moment $(p=0.016)$, and power $(p<0.001)$. No significant differences were found in knee angle during the vertical jumping phase.

Figure 6 displays the significant differences for hip angle, velocity, moment, and power during the vertical jumping phase between SJR and SJF. Significantly different values were hip angle $(p=0.008)$ and velocity $(p=0.012)$. No significant differences were found in hip moment and power during the vertical jumping phase.

\subsubsection{Vertical and Posterior Ground Reaction Force and Energy Work}

- Horizontal landing phase

Figure 7 displays the significant differences of the vertical and the sagittal ground reaction force during horizontal landing phase between SJR and SJF. Significantly different values were vertical ground reaction force $(p=0.007)(p=0.004)(p<0.001)$ and anterior and posterior ground reaction force $(p=0.048)(p=0.002)$. 

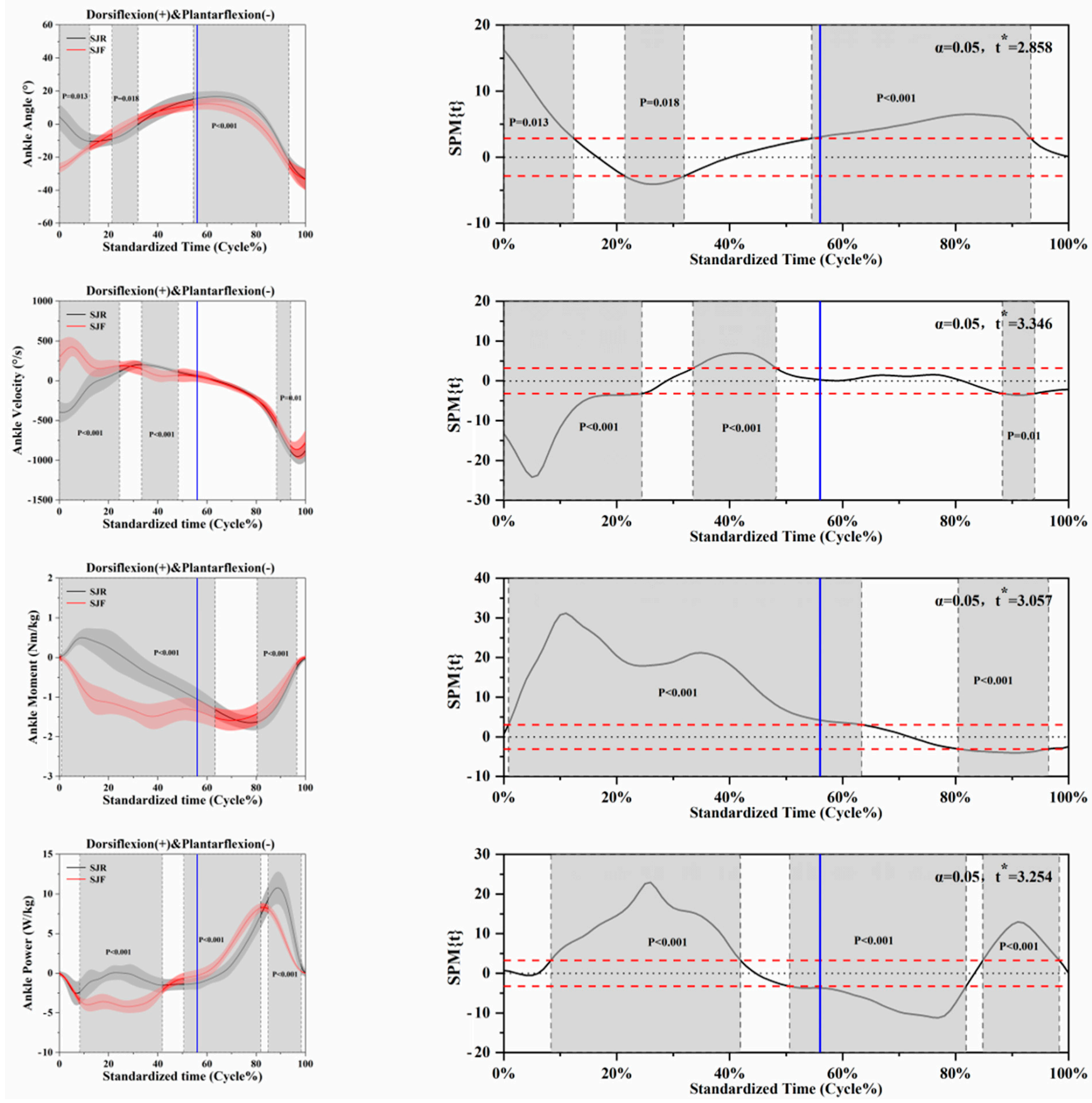

Figure 4. Illustration of results between SJR and SJF lower limb SPM results for angle, velocity, moment, and power of ankle during the stop-jumping phase, the SPM $\mathrm{t}$-values for all subjects (post hoc results, the lines of dashed red represent $p=0.05$ level). Statistically significant differences are shown in grey shaded areas to display regions. On the left of each image, the scale displays the change of joint angle, velocity, moment, and power. The value of $t^{*}$. 0-100 below each image presents a stop-jumping phase. In each picture, the initial ( $0 \%$ ) blue line is the horizontal landing phase, and the blue line toward the end $(100 \%)$ is the vertical jumping phase. 

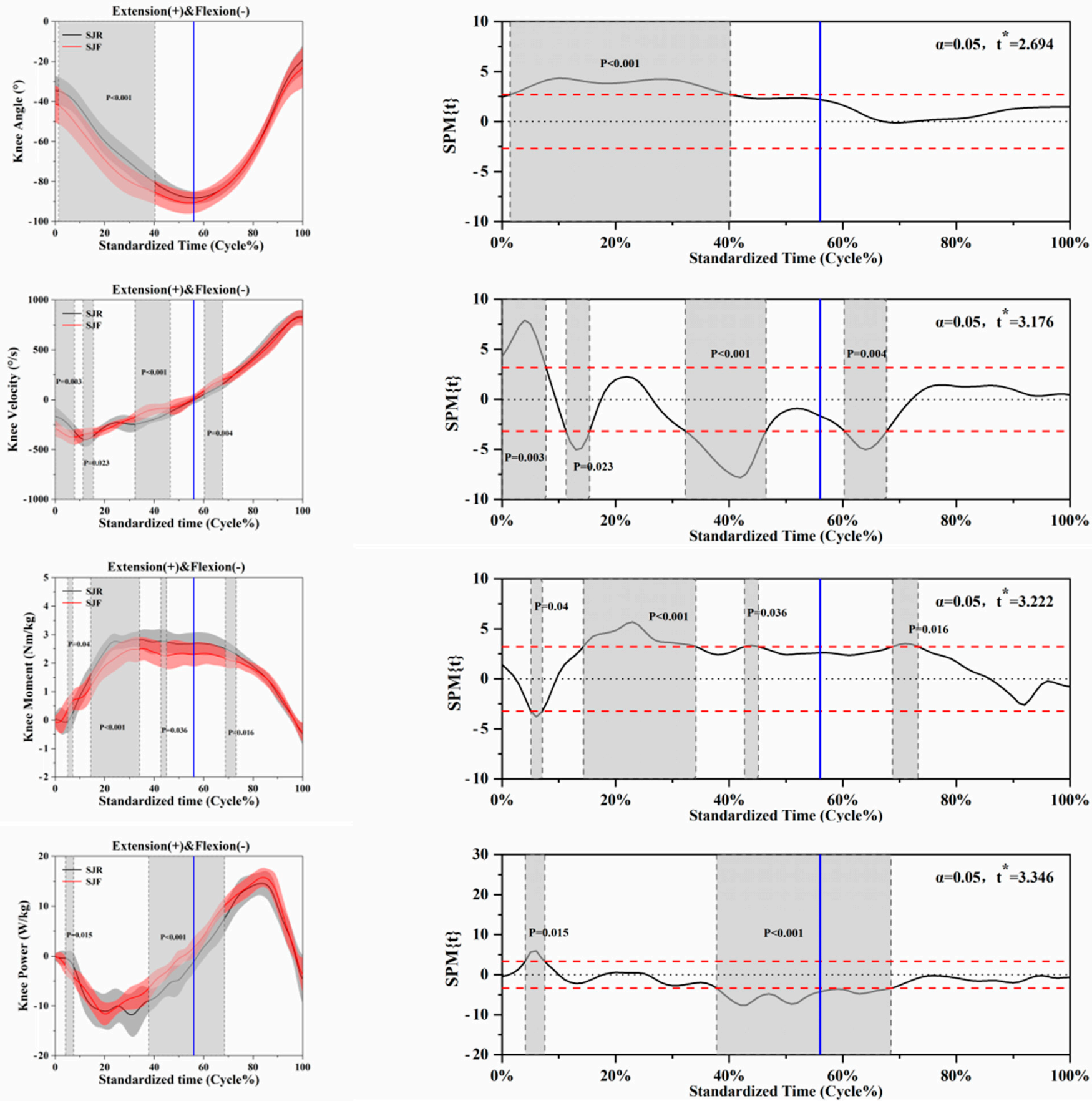

Figure 5. Illustration of results between SJR and SJF lower limb SPM results for angle, velocity, moment, and power of knee during the stop-jumping phase, the SPM t-values for all subjects (post hoc results, the lines of dashed red represent $p=0.05$ level). Statistically significant differences are shown in grey shaded areas to display regions. On the left of each image, the scale displays the change of joint angle, velocity, moment, and power. The value of $t^{*} .0-100$ below each image presents a stop-jumping phase. In each picture, the initial $(0 \%)$ blue line is the horizontal landing phase, and the blue line toward the end $(100 \%)$ is the vertical jumping phase. 

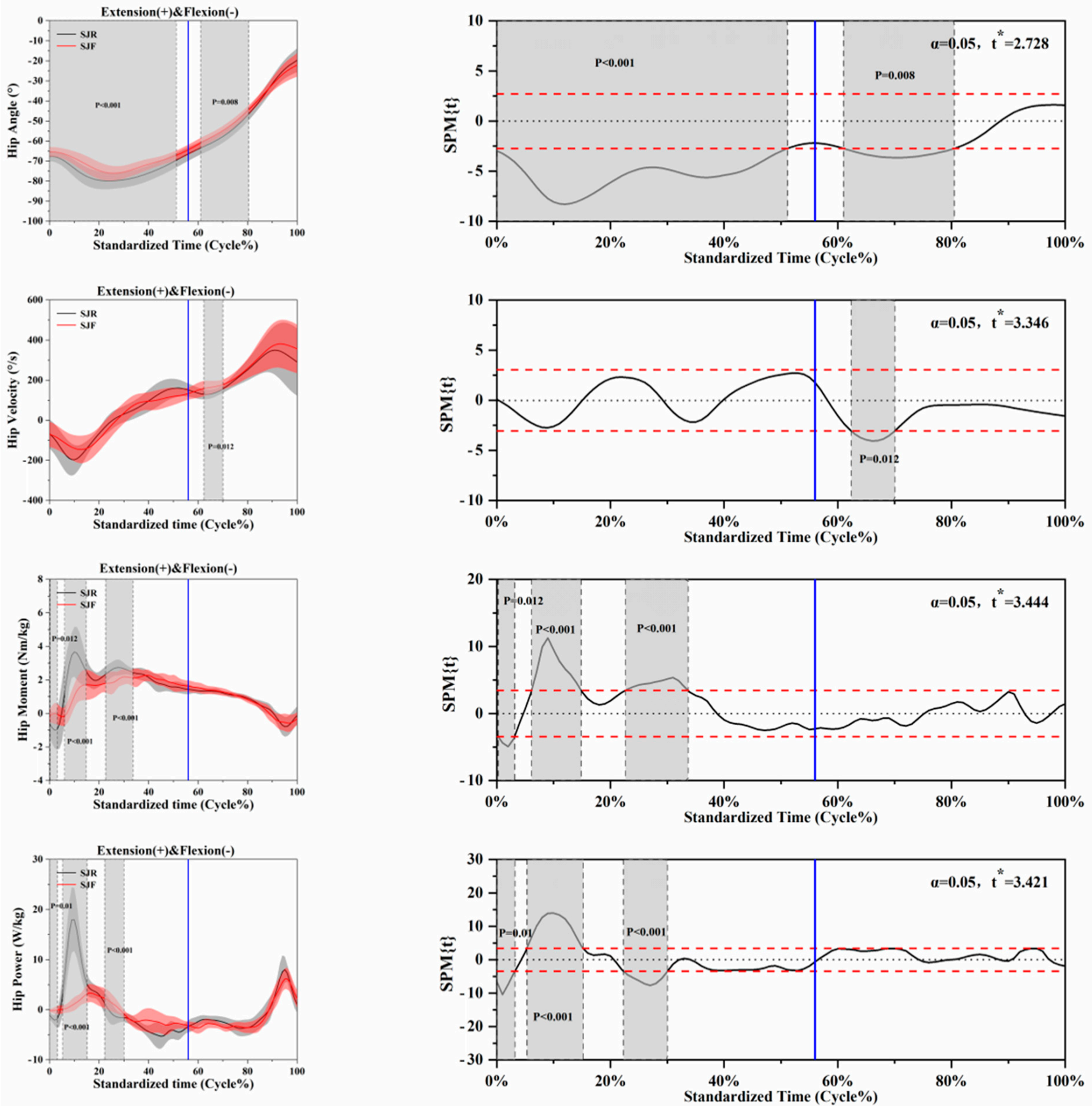

Figure 6. Illustration of results between SJR and SJF lower limb SPM results for angle, velocity, moment, and power of hip during the stop-jumping phase, the SPM t-values for all subjects (post hoc results, the lines of dashed red represent $p=0.05$ level). Statistically significant differences are shown in grey shaded areas to display regions. On the left of each image, the scale displays the change of joint angle, velocity, moment, and power. The value of $t^{*}$. $0-100$ below each image presents a stop-jumping phase. In each picture, the initial ( $0 \%$ ) blue line is the horizontal landing phase, and the blue line toward the end $(100 \%)$ is the vertical jumping phase. 

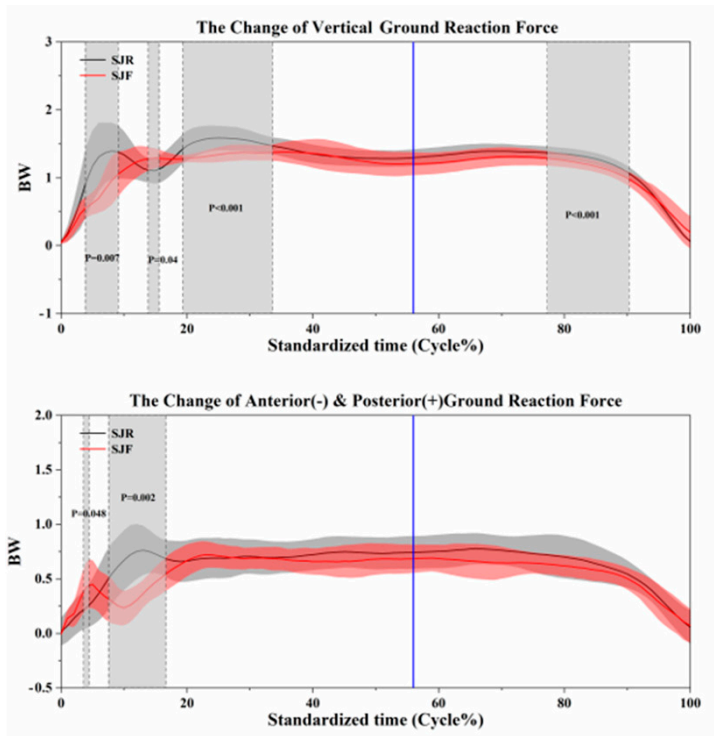
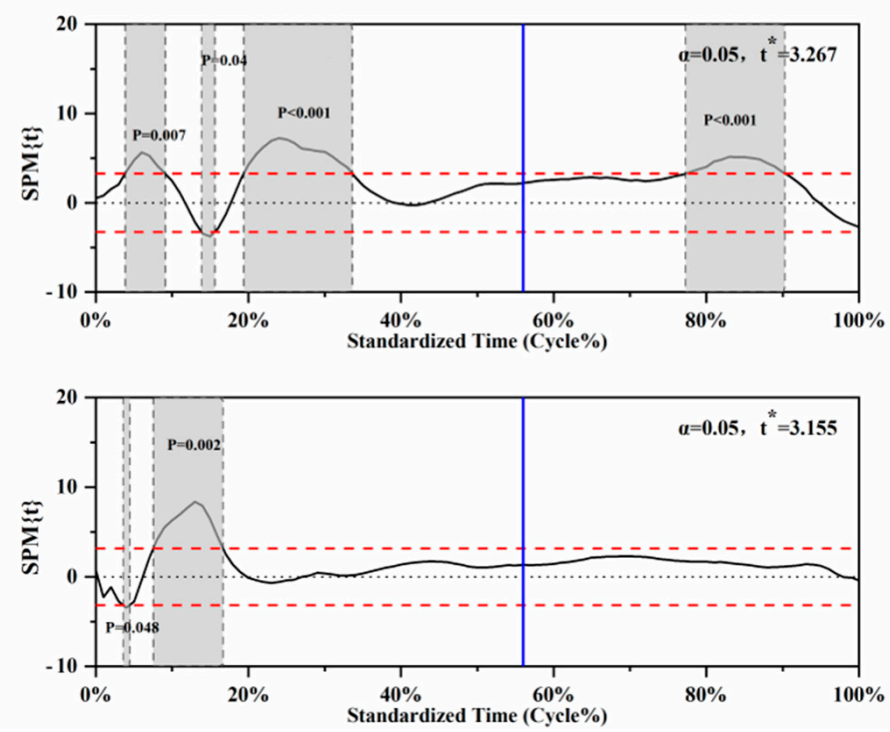

Figure 7. Descriptive results between SJR and SJF lower limb statistical parametric mapping results for the change of ground reaction force on the vertical and the sagittal planes during the stop-jumping phase, $t$-values of the SPM for all participants (post hoc results, dashed red lines represent $p=0.05$ level). Grey shaded areas display regions which have statistically significant differences. The scale on the left of each image shows the change in vertical and posterior ground reaction force. The value of $t^{*}$. 0-100 below each image presents a stop-jumping phase. In each picture, the initial ( $\left.0 \%\right)$ blue line is the horizontal landing phase, and the blue line toward the end (100\%) is the vertical jumping phase.

Figure 8 displays the significant differences of the sagittal plane energy distribution during the horizontal landing phase between SJR and SJF. Significantly different values were the ankle $(p=0.004)$ and the knee $(p=0.035)$.
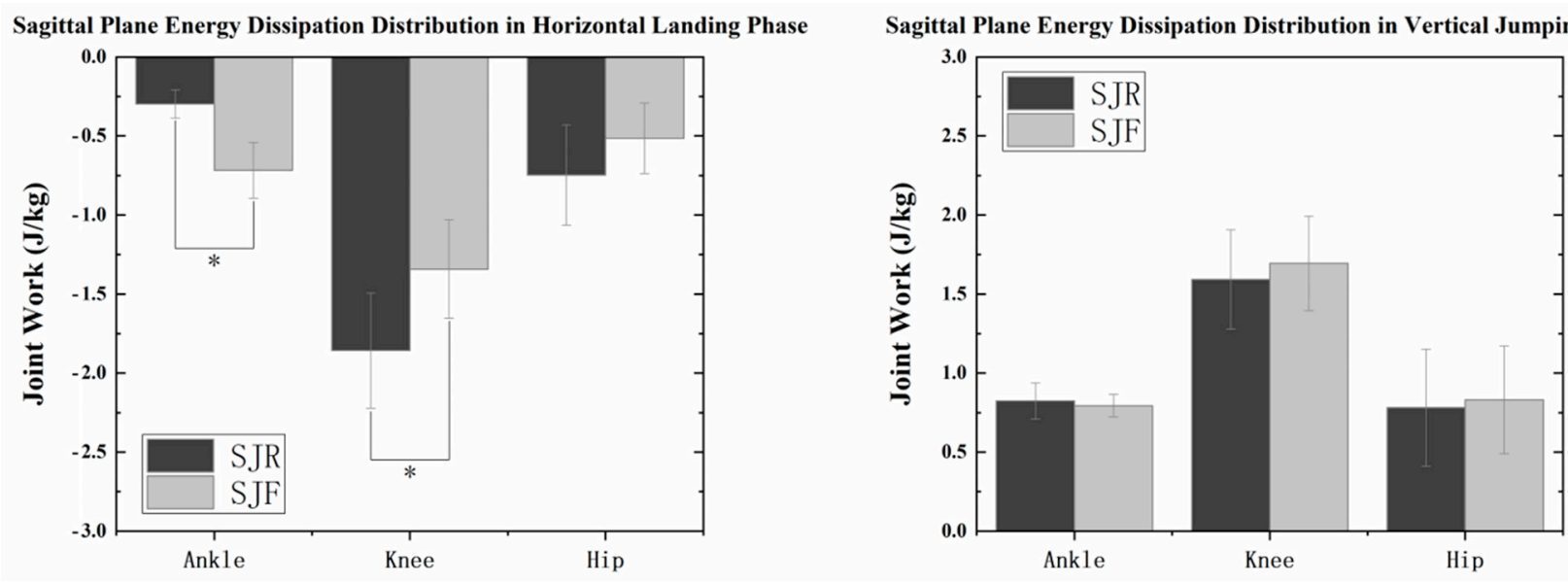

Figure 8. Comparison of mean energy dissipation and contribution in the sagittal plane between SJR and SJF lower limb during a stop-jumping phase. * indicates significant difference between SJR and SJF $(p<0.05)$.

- Vertical jumping phase

Figure 7 displays the significant differences for the vertical and the sagittal ground reaction forces during the vertical jumping phase between SJR and SJF. A significantly different value was the vertical ground reaction force $(p<0.001)$. No significant differences were found in anterior and posterior ground reaction forces during the vertical jumping phase.

No further significant differences were found on the sagittal plane energy dissipation distribution during the vertical jumping phase. 


\subsubsection{Proximal Tibia Anterior Shear Force and Vertical Joint Reaction Force}

\section{- Horizontal landing phase}

Figure 9 displays the significant differences in the vertical joint reaction force during the horizontal landing phase between SJR and SJF. Significantly different values were the vertical joint reaction force of ankle $(p=0.007)(p<0.001)(p=0.002)$, knee $(0.046)$, and hip $(p<0.038)$.
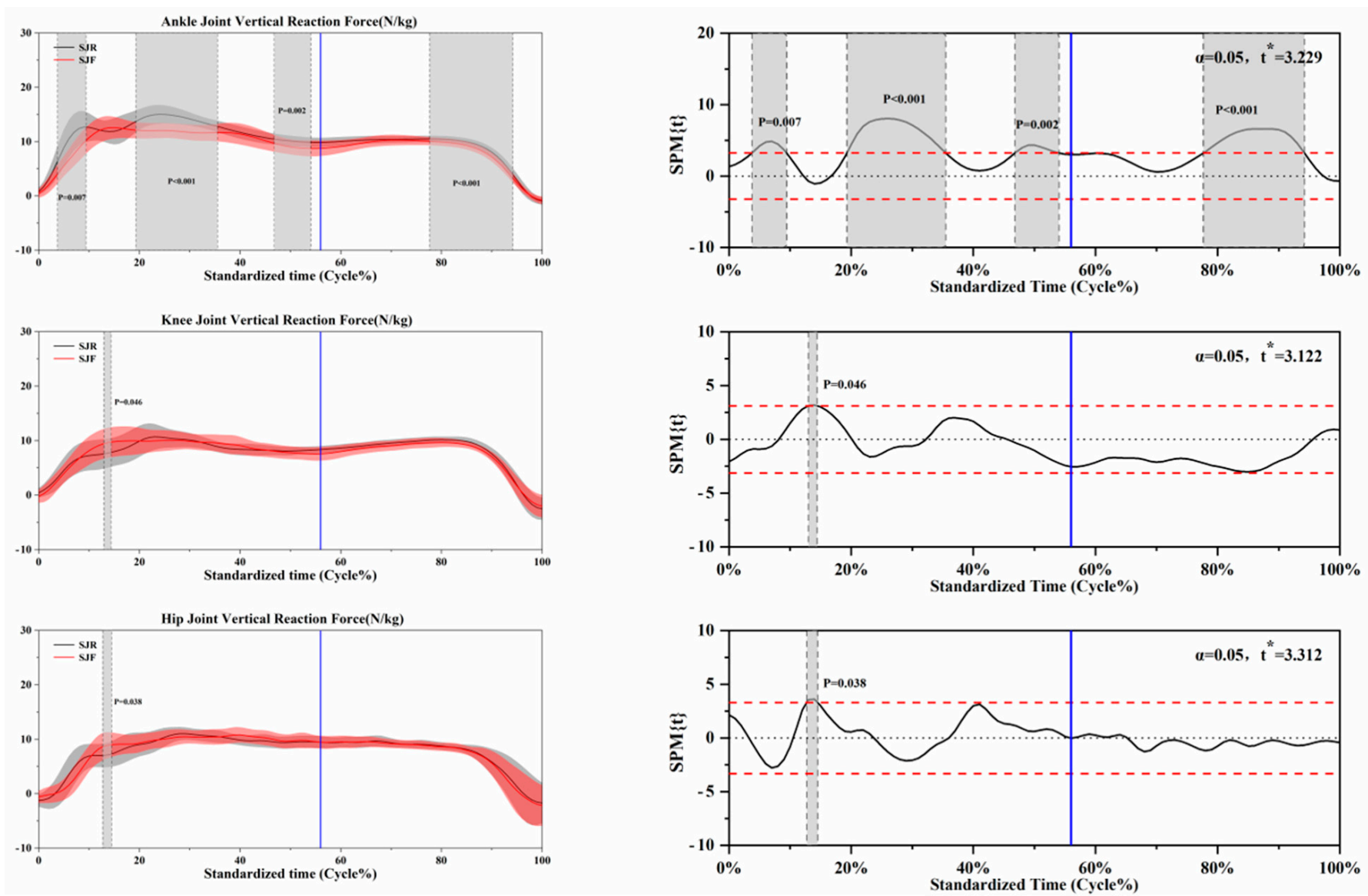

Figure 9. Descriptive results between SJR and SJF lower limb statistical parametric mapping results for the change of vertical joint reaction force on ankle, knee, and hip during the stop-jumping phase, $\mathrm{t}$-values of the SPM for all participants (post hoc results, dashed red lines represent $p=0.05$ level). Grey shaded areas display regions which have statistically significant differences. The scale on the left of each image shows the change in the vertical joint reaction force. The value of $t^{*}$. 0-100 below each image presents a stop-jumping phase. In each picture, the initial $(0 \%)$ blue line is the horizontal landing phase, and the blue line toward the end (100\%) is the vertical jumping phase.

There were no significant differences in PTASF (Figure 10) during the horizontal landing phase between SJR and SJF.

- Vertical jumping phase

Figure 9 displays the significant differences in the vertical joint reaction force during the vertical jumping phase between SJR and SJF. Significantly different values were the vertical joint reaction force of the ankle $(p<0.001)$. There were no further significant differences found for knee and hip joint vertical reaction forces during the vertical jumping phase between SJR and SJF.

No significant differences were found in PTASF (Figure 10) during the vertical jumping phase between SJR and SJF. 

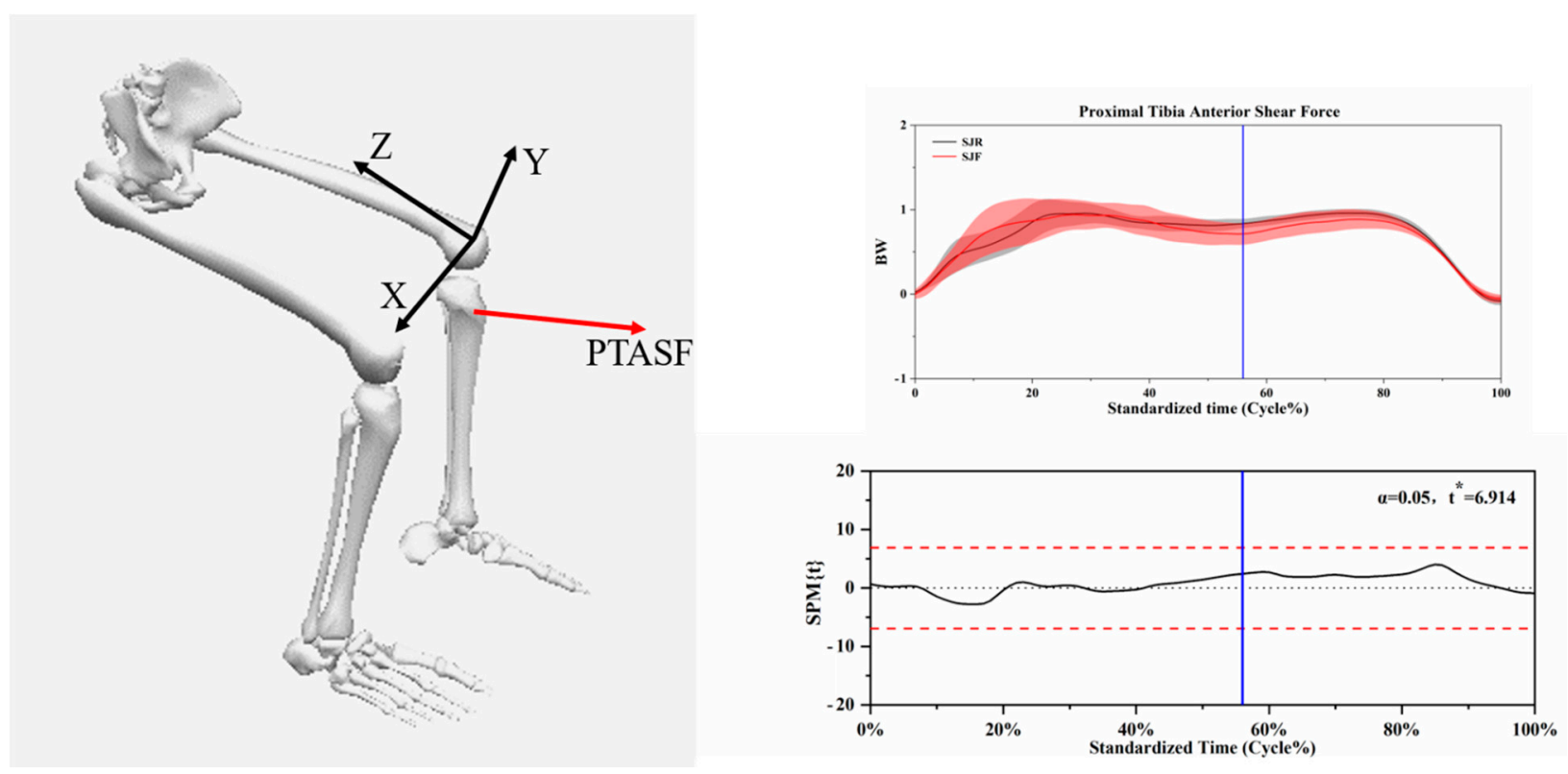

Figure 10. Descriptive results between SJR and SJF lower limb statistical parametric mapping results for the change of PTASF during the stop-jumping phase, $\mathrm{t}$-values of the SPM for all participants (post hoc results, dashed red lines represent $p=0.05$ level). The scale on the left of each image shows the change of PTASF. The value of $t^{*} .0-100$ below each image presents a stop-jumping phase. In each picture, the initial $(0 \%)$ blue line is the horizontal landing phase, and the blue line toward the end $(100 \%)$ is the vertical jumping phase.

\subsection{Traditional SPSS Analysis (Peak Variable)}

Table 2 displays that dorsiflexion of the angle of the ankle $(p=0.001)$, flexion of the knee $(p=0.021)$, and angle of the hip $(p<0.001)$ had significant differences between SJR and SJF during the stop-jumping phase. Additionally, dorsiflexion $(p<0.001)$ and plantarflexion $(p=0.014)$ of ankle velocity had significant differences between SJR and SJF during the stop-jumping phase.

Table 2. Comparison of the peak joint kinematics changes on the sagittal plane between SJR and SJF during the stop-jumping phase.

\begin{tabular}{|c|c|c|c|c|}
\hline $\begin{array}{l}\text { Joint Kinematics } \\
\text { on Sagittal Plane }\end{array}$ & Peak & SJR Mean \pm SD & SJF Mean \pm SD & $p$ Value \\
\hline Ankle Angle $\left(^{\circ}\right)$ & $\begin{array}{l}\text { Dorsiflexion } \\
\text { Plantarflexion }\end{array}$ & $\begin{array}{l}16.99(3.11) \\
-33.5(6.43)\end{array}$ & $\begin{array}{l}12.86(3.29) \\
-33.81(6.3)\end{array}$ & $\begin{array}{c}0.001 * \\
0.872\end{array}$ \\
\hline Knee Angle $\left(^{\circ}\right)$ & $\begin{array}{l}\text { Extension } \\
\text { Flexion }\end{array}$ & $\begin{array}{l}-18.99(7.19) \\
-88.63(3.18) \\
\end{array}$ & $\begin{array}{l}-23.03(10.31) \\
-91.16(5.67)\end{array}$ & $\begin{array}{c}0.141 \\
0.021 *\end{array}$ \\
\hline Hip Angle $\left({ }^{\circ}\right)$ & $\begin{array}{l}\text { Extension } \\
\text { Flexion }\end{array}$ & $\begin{array}{l}-19.68(6.08) \\
-80.51(3.91)\end{array}$ & $\begin{array}{l}-21.98(6.01) \\
-6.56(3.47)\end{array}$ & $\begin{array}{l}0.125 \\
<0.001 *\end{array}$ \\
\hline $\begin{array}{l}\text { Ankle Velocity } \\
\qquad(\% / \mathrm{s})\end{array}$ & $\begin{array}{c}\text { Dorsiflexion } \\
\text { Plantarflexion }\end{array}$ & $\begin{array}{c}220.95(36.07) \\
-968.31(92.94)\end{array}$ & $\begin{array}{c}475.64(112.44) \\
-883.18(105.34)\end{array}$ & $\begin{array}{l}<0.001 \text { * } \\
0.014 \text { * }\end{array}$ \\
\hline Knee Velocity $\left({ }^{\circ} / \mathrm{s}\right)$ & $\begin{array}{l}\text { Extension } \\
\text { Flexion }\end{array}$ & $\begin{array}{c}842.58(59.43) \\
-409.99(65.25)\end{array}$ & $\begin{array}{c}827.93(76.74) \\
-400.76(61.73)\end{array}$ & $\begin{array}{l}0.510 \\
0.495\end{array}$ \\
\hline Hip Velocity $(\% / s)$ & $\begin{array}{l}\text { Extension } \\
\text { Flexion }\end{array}$ & $\begin{array}{c}377.83(121.64) \\
-208.17(76.6)\end{array}$ & $\begin{array}{l}392.68(116.63) \\
-165.25(59.47)\end{array}$ & $\begin{array}{l}0.637 \\
0.054\end{array}$ \\
\hline
\end{tabular}

Table 3 displays that the dorsiflexion of ankle moment $(p<0.001)$, extension $(p=0.001)$ and flexion (0.015) of knee and extension $(p<0.001)$, and flexion $(p<0.001)$ of the hip moment had significant differences between SJR and SJF during the stop-jumping phase. Additionally, dorsiflexion $(p<0.001)$ and plantarflexion $(p<0.001)$ of ankle power 
and extension $(p<0.001)$ and flexion $(p=0.019)$ of hip power had significant differences between SJR and SJF during the stop-jumping phase.

Table 3. Comparison of the peak joint kinetics changes on the sagittal plane between SJR and SJF during the stop-jumping phase.

\begin{tabular}{ccccc}
\hline $\begin{array}{c}\text { Joint Kinetics } \\
\text { on Sagittal Plane }\end{array}$ & Peak & SJR Mean \pm SD & SJF Mean \pm SD & $p$ Value \\
\hline \multirow{2}{*}{ Ankle Moment $(\mathrm{Nm} / \mathrm{kg})$} & Dorsiflexion & $0.64(0.2)$ & $0.03(0.04)$ & $<0.001^{*}$ \\
& Plantarflexion & $-1.66(0.2)$ & $-1.65(0.29)$ & 0.910 \\
\cline { 2 - 5 } Knee Moment $(\mathrm{Nm} / \mathrm{kg})$ & Extension & $3.08(0.27)$ & $2.72(0.36)$ & $0.001^{*}$ \\
& Flexion & $-0.67(0.33)$ & $-0.47(0.34)$ & $0.015^{*}$ \\
\cline { 2 - 5 } Hip Moment $(\mathrm{Nm} / \mathrm{kg})$ & Extension & $4.18(1.23)$ & $2.76(0.44)$ & $<0.001^{*}$ \\
& Flexion & $-1.7(0.79)$ & $-0.99(0.3)$ & $<0.001^{*}$ \\
\cline { 2 - 5 } Ankle Power $(\mathrm{W} / \mathrm{kg})$ & Dorsiflexion & $11.26(2.04)$ & $8.39(0.56)$ & $<0.001^{*}$ \\
& Plantarflexion & $-3.36(1.26)$ & $-4.63(0.9)$ & $<0.001^{*}$ \\
\cline { 2 - 5 } Knee Power $(\mathrm{W} / \mathrm{kg})$ & Extension & $15.27(2.97)$ & $16.44(2.14)$ & 0.236 \\
& Flexion & $-13.99(3.97)$ & $-12.07(2.38)$ & 0.061 \\
\cline { 2 - 5 } Hip Power $(\mathrm{W} / \mathrm{kg})$ & Extension & $19.21(6.25)$ & $7.09(2)$ & $<0.001^{*}$ \\
& Flexion & $-6.33(1.83)$ & $-5.05(0.95)$ & $0.019^{*}$ \\
\hline
\end{tabular}

Note: Nm/kg: Newton meters per kilogram; W/kg: watts per kilogram; SD: standard deviation. " "* means significance with $p<0.05$.

Table 4 displays that peak VGRF $(p=0.009)$ and peak PGRF $(p=0.003)$ had significant differences between SJR and SJF during the stop-jumping phase.

Table 4. Comparison of the peak VGRF and PGRF changes between SJR and SJF during the stopjumping phase.

\begin{tabular}{cccc}
\hline Ground Reaction Force (BW). & SJR Mean \pm SD & SJF Mean \pm SD & $p$ Value \\
\hline Peak VGRF & $1.75(0.29)$ & $1.56(0.18)$ & $0.009^{*}$ \\
Peak PGRF & $0.95(0.15)$ & $0.83(0.11)$ & $0.003^{*}$ \\
\hline
\end{tabular}

Note: BW: body weight; SD: standard deviation. “*” means significance with $p<0.05$.

Table 5 shows peak ankle joint force $(p<0.001)$ had a significant difference between SJR and SJF during the stop-jumping phase.

Table 5. Comparison of the peak vertical joint force changes between SJR and SJF during the stop-jumping phase.

\begin{tabular}{cccc}
\hline Vertical Joint Force (N/kg) & SJR Mean \pm SD & SJF Mean \pm SD & $p$ Value \\
\hline Peak Ankle Joint Force & $16.04(1.97)$ & $14.04(1.49)$ & $<0.001^{*}$ \\
Peak Knee Joint Force & $11.71(1.45)$ & $11.18(1.92)$ & 0.410 \\
Peak Hip Joint Force & $11.62(1.22)$ & $11.55(1.39)$ & 0.793 \\
\hline
\end{tabular}

Note: Nm/kg: Newton meters per kilogram; SD: Standard deviation. " ${ }^{\text {"* }}$ means significance with $p<0.05$.

\section{Discussion}

This study aimed to compare lower limb stop-jumping results of the horizontal landing phase mechanics between SJF and SJR. A further aim was to compare the ability of stop-jumping phases to identify differences in stop-jumping horizontal landing phase mechanics. Our hypotheses were generally consistent with our results. We found that there are significant differences in biomechanical changes between two stop-jumping strategies, and our results indicate that SJF might reduce injuries when performed during a stop-jumping phase.

Our findings demonstrate that the larger ankle angle resulted in a significant difference in the horizontal landing phase of the knee joint during the two stop-jumping strategies. Lee proved that changes in the sagittal ankle angle during the landing phase can lead to 
a change in kinetics and kinematics of knee and hip joints [45]. This finding is consistent with our study. The knee joint in our study showed that SJF had higher knee flexion than SJR during the landing of the horizontal phase. The strategy of SJF increased the plantarflexion of ankle angle for simulating soft landing conditions during the landing of the horizontal phase. A previous study showed that a soft-landing strategy could lead to higher knee flexion, reducing landing impact force [46]. Additionally, actively changing the stiffness of the ankle is equivalent to increasing the range of motion [47]. However, this approach can alter the dynamics and the kinematics of the lower limbs, thus providing further evidence for our approach. The results of our study on moment provide further proof for our speculation. We can speculate that increasing the ankle angle of plantarflexion on the sagittal plane can increase the flexion of the knee during the horizontal landing phase. This could be due to the ankle joint sustaining more impact force for reducing knee joint impact force during the landing of the horizontal phase. However, although this approach reduces the probability of knee joint injury, it might increase the load of the ankle joint, resulting in ankle joint injury.

Interestingly, the previous study demonstrated that higher trunk flexion can be caused by higher flexion of the knee and the hip during the landing stage [46], and this approach can reduce knee and hip landing injuries. Compared with our study, there are increases in flexion of the knee and decreases in the moment of the knee joint during the horizontal landing stage. However, our results indicated that SJF has lower hip flexion and higher hip moment than SJR during the landing of the horizontal phase. This might be due to the instability of the ankle joint. A previous study demonstrated that one of the functions of the joint of the hip is supporting stability when performing a movement [48]. Combined with our results, it is desirable to decrease the impact of knee and hip joints by raising the plantarflexion of the ankle angle. This, however, may increase the amount of work done at the hip joint. Compared to SJR, SJF requires more work on the joint of the hip to increase the stability of the body to compensate for the instability caused by the ankle joint. According to the results from our hip moment data, SJR has a higher hip joint moment than SJF during the horizontal landing phase. This result further endorses our speculation.

In addition, the previous study demonstrated that raising the range of motion of the ankle joint increases its energy absorption, thereby reducing the energy absorption of knee and hip joints [49]. This is consistent with our study. SJF reduces the impact of hip and knee joints by increasing the range of motion of the ankle to absorb more impact. However, this approach may lead to fatigue caused by overuse of the ankle joint, resulting in potential injury. Regarding ground reaction forces, our results show that SJF has a lower VGRF than SJR. A previous study proved that raising the range of motion on the ankle joint can decrease VGRF during the landing phase [33]. This is consistent with the findings from our study, and our results show that, although the range of motion on the ankle joint can reduce VGRF, this strategy could result in the ankle suffering more impact force. Pain further demonstrated that VGRF is one of the most important parameters for reflecting patellar tendon injury [50]. According to this study, we can conclude that SJF might reduce landing injuries during the horizontal landing phase. Otherwise, our results indicate that SJR has a higher PGRF than SJF. A previous study proved that PGRF is one of the most important parameters for reflecting injury of ACL [3]. This further suggests that SJF could reduce lower limb injuries on the knee joint during the horizontal landing stage.

From the above analysis, it is not difficult to conclude that the ankle joint is particularly important in the horizontal landing of the stop-jumping phase. In this way, we can try to change our strategy of sharp stop-jumping as much as possible to reduce the risk of injury in the knee joint. However, this method has certain disadvantages for those who have a history of ankle injury or poor ankle strength, as this strategy may lead to further ankle injury. In addition, our guidelines are intended to reduce the risk of lower extremity injuries of the knee. If athletes want to reduce the risk of a knee injury, athletes need to strengthen ankle and hip joints. This strategy is an excellent method to reduce the injury risk for athletes who have knee injuries. There are some limitations to our study. 
Firstly, we only selected the dominant leg for testing, and the non-dominant leg is also an important factor during jumping and landing mechanical evaluations. Further research is required to investigate the mechanics associated with the non-dominant leg during the performance of jumping tasks. Secondly, only males were selected as subjects in this experiment. Previous studies have shown that females suffer more injuries on landing than men. Thirdly, we did not detect or examine changes in muscle function. This area also needs further biomechanical investigative study. Lastly, the stop-jumping on the rear foot or fore foot depends not only on the dominant foot but probably on left or right dominance as well.

\section{Conclusions}

In conclusion, this study analyzed and compared SJF and SJR by quantifying kinetics and kinematics changes during the stop-jumping phase. We found that altering the initial contact angle of the ankle might effectively reduce the risk of knee injury. We also compared previous studies with our results and found that SJF is an effective strategy to reduce lower limb injury during a stop-jumping phase. Further investigations should focus on the change of muscle work using electromyography and expand the sample size to validate our findings.

Author Contributions: Conceptualization, H.Z. and Y.G.; methodology, H.Z., D.X. and U.C.U.; software, H.Z. and U.C.U.; validation, H.Z. and D.X.; investigation, C.C., D.X. and U.C.U.; writingOriginal draft preparation, H.Z., C.C. and D.X.; writing-Review and editing, J.S.B. and Y.G.; All authors have read and agreed to the published version of the manuscript.

Funding: This study was funded by the Key Project of the National Social Science Foundation of China (19ZDA352), National Natural Science Foundation of China (No. 81772423), NSFC-RSE Joint Project (81911530253), and K. C. Wong Magna Fund in Ningbo University.

Institutional Review Board Statement: The study was conducted according to the guidelines of the Declaration of Helsinki and approved by the Ethics Committee of Ningbo University (protocol code RAGH 20200603).

Informed Consent Statement: Informed consent was obtained from all subjects involved in the study.

Data Availability Statement: Datasets for the current study are available from the corresponding author upon reasonable request.

Conflicts of Interest: The authors declare no conflict of interest.

\section{References}

1. Boden, B.P.; Dean, G.S.; Feagin, J.A.; Garrett, W.E. Mechanisms of anterior cruciate ligament injury. Orthopedics 2000, 23, 6. [CrossRef]

2. Yu, B.; Kirkendall, D.T.; Taft, T.N.; Garrett, W.E., Jr. Lower extremity motor control-related and other risk factors for noncontact anterior cruciate ligament injuries. Instr. Course Lect. 2002, 51, 315-324. [PubMed]

3. Edwards, S.; Steele, J.R.; Cook, J.L.; Purdam, C.R.; McGhee, D.E.; Munro, B.J. Characterizing patellar tendon loading during the landing phases of a stop-jump task. Scand. J. Med. Sci. Sports 2012, 22, 2-11. [CrossRef] [PubMed]

4. Zhou, H.; Ugbolue, U.C. Is there a relationship between strike pattern and injury during running: A review. Phys. Act. Health 2019, 3, 127-134. [CrossRef]

5. Yin, L.; Sun, D.; Mei, Q.; Gu, Y.; Baker, J.; Feng, N. The kinematics and kinetics analysis of the lower extremity in the landing phase of a stop-jump task. Open Biomed. Eng. J. 2015, 9, 103. [CrossRef] [PubMed]

6. Weinhold, P.S.; Stewart, J.-D.N.; Liu, H.-Y.; Lin, C.-F.; Garrett, W.E.; Yu, B. The influence of gender-specific loading patterns of the stop-jump task on anterior cruciate ligament strain. Injury 2007, 38, 973-978. [CrossRef]

7. Devita, P.; Skelly, W.A. Effect of landing stiffness on joint kinetics and energetics in the lower extremity. Med. Sci. Sports Exerc. 1992, 24, 108-115. [CrossRef]

8. Malinzak, R.A.; Colby, S.M.; Kirkendall, D.T.; Yu, B.; Garrett, W.E. A comparison of knee joint motion patterns between men and women in selected athletic tasks. Clin. Biomech. 2001, 16, 438-445. [CrossRef]

9. Chappell, J.D.; Yu, B.; Kirkendall, D.T.; Garrett, W.E. A comparison of knee kinetics between male and female recreational athletes in stop-jump tasks. Am. J. Sports Med. 2002, 30, 261-267. [CrossRef]

10. Onate, J.; Cortes, N. Gender Effect of Fatigue on Lower Extremity Kinematics and Kinetics During Athletic Tasks. ACL Inj. Female Athl. 2012, 221-234. [CrossRef] 
11. Decker, M.J.; Torry, M.R.; Wyland, D.J.; Sterett, W.I.; Steadman, J.R. Gender differences in lower extremity kinematics, kinetics and energy absorption during landing. Clin. Biomech. 2003, 18, 662-669. [CrossRef]

12. Arendt, E.A.; Agel, J.; Dick, R. Anterior cruciate ligament injury patterns among collegiate men and women. J. Athl. Train. 1999, $34,86$.

13. Arendt, E.; Dick, R. Knee injury patterns among men and women in collegiate basketball and soccer: NCAA data and review of literature. Am. J. Sports Med. 1995, 23, 696-701. [CrossRef] [PubMed]

14. Yu, B.; Herman, D.; Preston, J.; Lu, W.; Kirkendall, D.T.; Garrett, W.E. Immediate effects of a knee brace with a constraint to knee extension on knee kinematics and ground reaction forces in a stop-jump task. Am. J. Sports Med. 2004, 32, 1136-1143. [CrossRef] [PubMed]

15. Buff, H.-U.; Jones, L.C.; Hungerford, D.S. Experimental determination of forces transmitted through the patello-femoral joint. J. Biomech. 1998, 21, 17-23. [CrossRef]

16. Grood, E.S.; Suntay, W.J.; Noyes, F.R.; Butler, D. Biomechanics of the knee-extension exercise. Effect of cutting the anterior cruciate ligament. J. Boen. Joint. Surg. Am. 1984, 66, 725-734. [CrossRef]

17. Markolf, K.L.; Gorek, J.F.; Kabo, J.M.; Shapiro, M.S. Direct measurement of resultant forces in the anterior cruciate ligament. An in vitro study performed with a new experimental technique. J. Bone Jt. Surg. 1990, 72, 557-567. [CrossRef]

18. Smidt, G.L. Biomechanical analysis of knee flexion and extension. J. Biomech. 1973, 6, 79-92. [CrossRef]

19. Van Eijden, T.; De Boer, W.; Weijs, W. The orientation of the distal part of the quadriceps femoris muscle as a function of the knee flexion-extension angle. J. Biomech. 1985, 18, 803-809. [CrossRef]

20. Paterno, M.V.; Rauh, M.J.; Schmitt, L.C.; Ford, K.R.; Hewett, T.E. Incidence of second ACL injuries 2 years after primary ACL reconstruction and return to sport. Am. J. Sports Med. 2014, 42, 1567-1573. [CrossRef]

21. Webster, K.E.; Feller, J.A. Exploring the high reinjury rate in younger patients undergoing anterior cruciate ligament reconstruction. Am. J. Sports Med. 2016, 44, 2827-2832. [CrossRef] [PubMed]

22. Butler, R.J.; Dai, B.; Huffman, N.; Garrett, W.E.; Queen, R.M. Lower extremity movement differences persist after anterior cruciate ligament reconstruction and when returning to sports. Clin. J. Sports Med. 2016, 26, 411-416. [CrossRef] [PubMed]

23. Dai, B.; Butler, R.; Garrett, W.; Queen, R. Using ground reaction force to predict knee kinetic asymmetry following anterior cruciate ligament reconstruction. Scand. J. Med. Sci. Sports 2014, 24, 974-981. [CrossRef] [PubMed]

24. Xu, D.; Jiang, X.; Cen, X.; Julien, S.B.; Gu, Y.D. Single-Leg Landings Following a Volleyball Spike May Increase the Risk of Anterior Cruciate Ligament Injury More Than Landing on Both-Legs. Appl. Sci. 2021, 11, 130. [CrossRef]

25. Xu, D.; Lu, J.; Baker, J.S.; Gus, F.; Gu, Y.D. Temporal kinematic and kinetics differences throughout different landing ways following volleyball spike shots. Proc. Inst. Mech. Eng. Part P J. Sports Eng. Technol. 2021. [CrossRef]

26. Renner, K.E.; Franck, C.T.; Miller, T.K.; Queen, R.M. Limb asymmetry during recovery from anterior cruciate ligament reconstruction. J. Orthop. Res. 2018, 36, 1887-1893. [CrossRef]

27. Schmitt, L.C.; Paterno, M.V.; Ford, K.R.; Myer, G.D.; Hewett, T.E. Strength asymmetry and landing mechanics at return to sport after ACL reconstruction. Med. Sci. Sports Exerc. 2015, 47, 1426. [CrossRef]

28. Maletius, W.; Messner, K. Eighteen-to twenty-four-year follow-up after complete rupture of the anterior cruciate ligament. Am. J. Sports Med. 1999, 27, 711-717. [CrossRef]

29. Yu, B.; Garrett, W.E. Mechanisms of non-contact ACL injuries. Brit. J. Sports Med. 2007, 41, i47-i51. [CrossRef]

30. McNair, P.; Marshall, R.; Matheson, J. Important features associated with acute anterior cruciate ligament injury. N. Z. Med. J. 1990, 103, 537-539.

31. Olsen, O.-E.; Myklebust, G.; Engebretsen, L.; Bahr, R. Injury mechanisms for anterior cruciate ligament injuries in team handball: A systematic video analysis. Am. J. Sports Med. 2004, 32, 1002-1012. [CrossRef]

32. Sell, T.C.; Ferris, C.M.; Abt, J.P.; Tsai, Y.S.; Myers, J.B.; Fu, F.H.; Lephart, S.M. Predictors of proximal tibia anterior shear force during a vertical stop-jump. J. Orthop. Res. 2007, 25, 1589-1597. [CrossRef]

33. McNitt-Gray, J.L. Kinetics of the lower extremities during drop landings from three heights. J. Biomech. 1993, $26,1037-1046$. [CrossRef]

34. Zhou, H.; Chen, C.; Xu, D.; Ukadike, C.U.; Gu, Y.D.; Baker, J.S. Biomechanical Characteristics between Bionic Shoes and Normal Shoes during the Drop-Landing Phase: A Pilot Study. Int. J. Environ. Res. Public Health 2021, 18, 3223. [CrossRef] [PubMed]

35. Malliaras, P.; Cook, J.; Ptasznik, R.; Thomas, S. Prospective study of change in patellar tendon abnormality on imaging and pain over a volleyball season. Br. J. Sports Med. 2006, 40, 272-274. [CrossRef]

36. Cappozzo, A.; Cappello, A.; Croce, U.D.; Pensalfini, F. Surface-marker cluster design criteria for 3-D bone movement reconstruction. IEEE Trans. Biomed. Eng. 1997, 44, 1165-1174. [CrossRef] [PubMed]

37. Butler, R.J.; Willson, J.D.; Fowler, D.; Queen, R.M. Gender differences in landing mechanics vary depending on the type of landing. Clin. J. Sport Med. 2013, 23, 52-57. [CrossRef] [PubMed]

38. Myers, C.A.; Hawkins, D. Alterations to movement mechanics can greatly reduce anterior cruciate ligament loading without reducing performance. J. Biomech. 2010, 43, 2657-2664. [CrossRef]

39. Yu, B.; Lin, C.-F.; Garrett, W.E. Lower extremity biomechanics during the landing of a stop-jump task. Clin. Biomech. 2006, 21, 297-305. [CrossRef] [PubMed]

40. Cowley, H.R.; Ford, K.R.; Myer, G.D.; Kernozek, T.W.; Hewett, T.E. Differences in neuromuscular strategies between landing and cutting tasks in female basketball and soccer athletes. J. Athl. Train. 2006, 41, 67. 
41. Xu, D.; Cen, X.; Wang, M.; Rong, M.; István, B.; Baker, J.S.; Gu, Y. Temporal Kinematic Differences between Forward and Backward Jump-Landing. Int. J. Environ. Res. Public Health 2020, 17, 6669. [CrossRef]

42. Xu, D.; Lu, Z.; Shen, S.; Gus, F.; Ukadike, C.U.; Gu, Y.D. The Differences in Lower Extremity Joints Energy Dissipation Strategy during Landing between Athletes with Symptomatic Patellar Tendinopathy (PT) and without Patellar Tendinopathy (UPT). Mol. Cell. Biomech. 2021, 18, 2. [CrossRef]

43. Howe, L.P.; Bampouras, T.M.; North, J.; Waldron, M. Ankle dorsiflexion range of motion is associated with kinematic but not kinetic variables related to bilateral drop-landing performance at various drop heights. Hum. Mov. Sci. 2019, 64, 320-328. [CrossRef] [PubMed]

44. Pataky, T.C.; Robinson, M.A.; Vanrenterghem, J. Vector field statistical analysis of kinematic and force trajectories. J. Biomech. 2013, 46, 2394-2401. [CrossRef]

45. Lee, J.; Song, Y.; Shin, C.S. Effect of the sagittal ankle angle at initial contact on energy dissipation in the lower extremity joints during a single-leg landing. Gait Posture 2018, 62, 99-104. [CrossRef] [PubMed]

46. Blackburn, J.T.; Padua, D.A. Influence of trunk flexion on hip and knee joint kinematics during a controlled drop landing. Clin. Biomech. 2008, 23, 313-319. [CrossRef] [PubMed]

47. Whitting, J.W.; Steele, J.R.; Mcghee, D.E.; Munro, B.J. Dorsiflexion capacity affects achilles tendon loading during drop landings. Med. Sci. Sports Exerc. 2011, 43, 706-713. [CrossRef] [PubMed]

48. Singleton, M.C.; LeVeau, B.F. The hip joint: Structure, stability, and stress: A review. Phys. Ther. 1975, 55, 957-973. [CrossRef] [PubMed]

49. Peng, H.-T. Changes in biomechanical properties during drop jumps of incremental height. J. Strength Cond. Res. 2011, 25, 2510-2518. [CrossRef]

50. Pain, M.T.; Challis, J.H. The influence of soft tissue movement on ground reaction forces, joint torques and joint reaction forces in drop landings. J. Biomech. 2006, 39, 119-124. [CrossRef] 